\title{
Acute Myocardial Infarction. Clinical and Epidemiological Profile and Factors Associated with In-Hospital Death in the Municipality of Rio de Janeiro
}

\author{
Claudia Caminha Escosteguy, Margareth Crisóstomo Portela, Roberto de Andrade Medronho, \\ Maurício Teixeira Leite de Vasconcellos \\ Rio de Janeiro, RJ - Brazil
}

\begin{abstract}
Objective - To study the factors associated with the risk of in-hospital death in acute myocardial infarction in the Brazilian public health system in Rio de Janeiro, Brazil.

Methods - Sectional study of a sample with 391 randomly drawn medical records of the hospitalizations due to acute myocardial infarction recorded in the hospital information system in 1997.
\end{abstract}

Results - The diagnosis was confirmed in $91.7 \%$ of the cases; $61.5 \%$ males; age $=60.2 \pm 2.4$ years; delta time until hospitalization of 11 hours; $25.3 \%$ were diabetic; $58.1 \%$ were hypertensive; $82.6 \%$ were in Killip I class. Inhospital mortality was $20.6 \%$. Thrombolysis was used in 19.5\%; acetylsalicylic acid (ASA) $86.5 \%$; beta-blockers 49\%; angiotensin-converting enzyme (ACE) inhibitors 63.3\%; calcium channel blockers $30.5 \%$. Factors associated with increased death: age (61-80 years: $O R=2.5$; > 80years: $O R=9.6$ ); Killip class (II: $O R=1.9 ;$ III: $O R=6 ; I V$ : $O R=26.5)$; diabetes $(O R=2.4)$; ventricular tachycardia $(O R=8.5)$; ventricular fibrillation $(O R=34)$; recurrent ischemia $(O R=2.7)$. The use of ASA $(O R=0.3)$, beta-blockers $(O R=0.3)$, and $A C E$ inhibitors $(O R=0.4)$ was associated with a reduction in the chance of death.

Conclusion-General lethality was high and some interventions of confirmed efficacy were underutilizated. The logistic model showed the beneficial effect of beta-blockers, and ACE inhibitors on the risk of in-hospital death.

Keywords: acute myocardial infarction; in-hospital mortality; multivariate analysis

Hospital dos Servidores do Estado/SUS/Rio de Janeiro

Mailing address: Claudia Caminha Escosteguy - Av. Alexandre Ferreira, 361 22470-220 - Rio de Janeiro, RJ, Brazil - E-mail: cescosteguy@hse.saude.gov.br English version by Stela Maris C. e Gandour
Cardiovascular diseases play a relevant role as indicators of morbidity and mortality in Brazil and are the first cause of proportional mortality in the country since the 1960s. In $1998,25 \%$ of male deaths and $31.3 \%$ of female deaths were caused by cardiovascular diseases ${ }^{1}$. Ischemic heart disease, including acute myocardial infarction, is the major cause of death in the cities in the southern and southeastern regions ${ }^{1,2}$.

Acute myocardial infarction is an acute event that always requires hospitalization. Its clinical diagnosis is relatively simple and well established and is usually based on the triad, clinical history, electrocardiographic evolution, and enzymatic curve ${ }^{3,4}$. The management of acute myocardial infarction comprises several therapeutical options with scientifically confirmed efficacy, which have been discussed extensively throughout the practical guidelines of several international societies and those of the Brazilian Society of Cardiology 3,5 .

However, some studies have shown that the existence of or even knowledge about these guidelines has not assured treatment practices based on scientific evidence. The variability in the use of therapeutic interventions in acute myocardial infarction reported in the literature is great, and many times shows the nonadherence to wellestablished protocols ${ }^{6-16}$. Recently, a study about the profiles of pharmacological treatment in acute myocardial infarction in the municipality of Rio de Janeiro showed the underutilization of interventions of confirmed efficacy in acute myocardial infarction, such as the use of intravenous thrombolytic agents, of acetylsalicylic acid, of I.V. betablockers, and of I.V. nitrates, and a relatively widespread use of calcium channel blockers not based on scientific evidence ${ }^{17}$.

In-hospital mortality has been reported to vary greatly, and, among other reasons, it may be related to differences in the severity of the cases and to differences in the quality of medical treatment ${ }^{7,10-15,17-22}$. 
Considering all that, this study aimed at analyzing the clinical and epidemiological profile of a representative sample of acute myocardial infarction treated at the Sistema Único de Saúde (SUS - Brazilian public health system) in the municipality of Rio de Janeiro. The major factors associated with the variation in the risk of in-hospital death, including those related to the severity of the cases and the process of medical assistance, were identified.

\section{Methods}

A sectional study of a random sample of 391 medical records was carried out. The sample was stratified according to the hospitals, drawn from a total of 1,936 hospitalizations recorded with the main diagnosis of acute myocardial infarction based on the AIH (Authorization for Hospitalization) of the system of hospital information (SIH/SUS) in the municipality of Rio de Janeiro in 1997. The calculation of the size of the sample considered the proportion of patients and deaths with a relative error of $10 \%$ and a significance level of $5 \%$ in a stratified sample model with proportional allocation and no reposition ${ }^{23}$. The patients were randomly drawn from 22 hospitals included in the sample, which were chosen from the initial universe of 38 hospitals. Hospitals treating less than 10 cases in the year studied were excluded from the study. The field work comprised data collection in the medical records to confirm the diagnosis of acute myocardial infarction, data about risk factors and the severity of the disease, and data about the use of diagnostic and therapeutic interventions, and was reported in detail in another publication ${ }^{24}$. The study protocol was approved by the committee on ethics in research of the Escola Nacional de Saúde Pública/FIOCRUZ.

The diagnosis of acute myocardial infarction was confirmed according to the criteria of definitive or probable cases adopted by the MONICA Project of the World Health Organization ${ }^{25}$. The clinical classification of the hemodynamic status of patients was performed according to Killip \& Kimball $^{26}$.

Univariate and multivariate analyses were performed with the Epi Info 6.04d and SAS ${ }^{\mathrm{TM}}$ (6.0 version) programs. The $\chi^{2}$ test was used to check the statistical significance of the differences observed in the proportions of the categories of the variables studied; a 2 -tailed $p<0.05$ was considered statistically significant. When necessary, the Fisher exact test was used. Confidence intervals of $95 \%(95 \% \mathrm{CI})$ of the estimated proportions and odds ratio (OR) were calculated. To study the factors associated with the variation in the risk of in-hospital death, multivariate analysis with logistic regression was used; in this case, the Wald test was used to check the significance of the independent variables included in the model. To analyze the overall adjustment of the model, the test of likelihood ratio (-2 LOG L) was used. The following parameters were analyzed: the concordance between the probabilities foretold by the model and the responses observed; the presence of interaction between the variables; the diagnosis of regression through the analysis of the residues and extreme observations, and its possible impact on the model. Through hierarchic modeling, the random effect on the level of the hospitals was tested based on the hypothesis of the existence of an intraclass correlation relative to the hospital units.

\section{Results}

Three hundred and eighty-four of the 391 randomly drawn medical records were reviewed (loss of $1.8 \%$ ). The diagnosis of acute myocardial infarction was confirmed in $91.7 \%(95 \% \mathrm{CI}=88.3-94.2)$ of the patients according to the already cited criteria. Of the patients, $61.5 \%$ were males and $38.5 \%$ were females, and their mean age was $60.2+2.4$ years. The time interval (delta time) between symptom onset and hospitalization was up to 6 hours in $21.9 \%$ of the patients; the median delta time was 11 hours. The analysis of delta time was limited to a percentage, of missing data of $37.8 \%$, most of the time due to lack of a report in the medical records. In-hospital mortality was $20.6 \%(95 \% \mathrm{CI}=16.7-25.0)$.

The clinical findings at presentation were typical of acute myocardial infarction in 313 cases $(81.5 \%) ; 16(4.2 \%)$ patients had no presentation findings reported in their medical records. In 21 of the remaining 55 cases, chest pain noncharacteristic of acute myocardial infarction was reported; 14 patients presented with left ventricular failure; in 6 (14.3\%) patients, cardiopulmonary arrest was reported; 3 occurred after a cardiac procedure; 2 occurred after a noncardiac surgery; the remaining varied.

The municipality of residence was Rio de Janeiro in $80.7 \%$ of the cases; $11.7 \%$ lived in the municipalities of the Baixada Fluminense (a region in the state of Rio de Janeiro). Of the cases, $29.7 \%$ came from public emergency departments [usually from the hospital issuing the AIH (Authorization for Hospitalization)] and $10.9 \%$ from health care units or public outpatient care units; however, the percentage of ignored place of origin was high (25.5\%).

Table I shows the distribution of some characteristics of the sample. For risk factors, such as obesity and sedentary lifestyle, the lack of information in the medical records was so high $(67.1 \%$ and $78 \%)$ that it made the analysis unfeasible. Of the risk factors, the information about arterial hypertension and diabetes mellitus had the greatest quality. These 2 factors prevailed in females (hypertension: $64.2 \%$ vs $54.2 \%$; $\mathrm{p}=0.02$; diabetes: $32.4 \%$ vs $20.8 \%$; $\mathrm{p}=0.03$ ). Except for sex, age group, and Killip class on admission, the distribution of the factors shown in table I varied widely among the hospitals in the sample, which were previously detailed ${ }^{24}$.

The 28 patients, whose Killip classes on admissionhad not been reported, were as follows: 3 had associated respiratory findings, which prevented classification; 5 had left ventricular failure reported with no Killip classification; and in 20, the information was not available in the medical records. High lethality was observed in these 28 cases. During hospitalization, $65.4 \%$ of the patients remained in Killip I.

Table II shows the frequency of some complications with the respective lethalities. In addition, 1 case of pulmo- 


\begin{tabular}{|c|c|c|c|c|c|c|c|}
\hline Factor & $\mathrm{f}$ & $\%$ & $95 \% \mathrm{CI}$ & Lethality (\%) & $\mathrm{OR}^{1}$ & $95 \% \mathrm{CI}$ & $\mathrm{p}$ \\
\hline \multicolumn{8}{|l|}{ Sex } \\
\hline Male & 236 & 61.5 & $56.4-66.3$ & 17.8 & 1 & - & - \\
\hline Female & 148 & 38.5 & $33.7-43.6$ & 25 & 1.5 & $0.9-2.6$ & 0.09 \\
\hline \multicolumn{8}{|l|}{ Age group ${ }^{2}$} \\
\hline$\leq 60 \mathrm{y}$ & 187 & 49 & $43.8-54.1$ & 12.8 & 1 & - & - \\
\hline $61-80 y$ & 180 & 47.1 & $42-52.3$ & 25.6 & 2.7 & $1.3-4.2$ & 0.002 \\
\hline$>80 \mathrm{y}$ & 15 & 3.9 & $2.3-6.5$ & 53.3 & 7.8 & $2.3-26.7$ & 0.0005 \\
\hline \multicolumn{8}{|c|}{ Killip class on admission } \\
\hline I & 317 & 82.6 & $78.3-86.1$ & 12.3 & 1 & - & - \\
\hline II & 19 & 5 & $3.1-7.8$ & 42.1 & 5.2 & $1.8-15$ & 0.002 \\
\hline III & 9 & 2.3 & $1.1-5.2$ & 55.6 & 8.9 & $2-41.7$ & 0.003 \\
\hline IV & 11 & 2.9 & $1.5-5.2$ & 90.9 & 71.3 & $9 \quad-1.524$ & $<0.000001$ \\
\hline Not reported & 28 & 7.3 & $5-10.5$ & 60.7 & 11 & $4.5-27.4$ & $<0.000001$ \\
\hline Arterial hypertension & 223 & 58.1 & $53-63$ & 17.9 & 2 & $0.9-4.8$ & 0.06 \\
\hline Smoking & 160 & 41.7 & $36.7-46.6$ & 13.1 & 1.2 & $0.5-2.8$ & NS \\
\hline Diabetes mellitus & 97 & 25.3 & $21.1-30$ & 27.8 & 4.2 & $2-9$ & 0.00003 \\
\hline Dyslipidemia & 71 & 18.5 & $14.8-22.8$ & 9.9 & 3 & $0.6-18.3$ & NS \\
\hline Familial history & 96 & 25 & $20.8-29.7$ & 13.5 & 1.9 & $0.6-7.1$ & NS \\
\hline Previous infarction & 61 & 15.9 & $12.5-20$ & 18 & 1.9 & $0.7-4.7$ & NS \\
\hline Previous angina & 154 & 40.1 & $35.2-45.2$ & 15.6 & 1.3 & $0.4-4.7$ & NS \\
\hline Previous stroke & 21 & 5.5 & $3.5-8.4$ & 19.5 & 2 & $0.5-7.1$ & NS \\
\hline
\end{tabular}

\begin{tabular}{|c|c|c|c|c|c|c|c|}
\hline Complication & $\mathrm{f}$ & $\%$ & $95 \% \mathrm{CI}$ & Lethality $(\%)$ & $\mathrm{OR}^{1}$ & $95 \% \mathrm{CI}$ & $\mathrm{p}$ \\
\hline Post-AMI angina & 69 & 18 & $14.3-22.3$ & 20.3 & 1 & $0.5-2$ & NS \\
\hline Reinfarction & 9 & 2.3 & $1.1-4.6$ & 44.4 & 3.2 & $0.7-15.2$ & NS \\
\hline Recurring ischemia ${ }^{2}$ & 72 & 18.8 & $\begin{array}{ll}15 & -23.1\end{array}$ & 22.2 & 1.4 & $0.7-2.7$ & NS \\
\hline Ventricular tachycardia & 17 & 4.4 & $2.7-7.1$ & 52.6 & 4.8 & $1.7-13.4$ & 0.001 \\
\hline Ventricular fibrillation & 17 & 4.4 & $2.7-7.1$ & 76.5 & 14.8 & $4.3-63.7$ & $<0.00001$ \\
\hline Primary cardiac arrest & 19 & 4.9 & $3.1-7.8$ & 84.2 & 25.6 & $6.9-139.2$ & $<0.00001$ \\
\hline Left or right bundle-branch block & 31 & 8.1 & $5.6-11.4$ & 45.2 & 3.7 & $1.6-8.3$ & 0.0004 \\
\hline Atrial fibrillation/flutter & 21 & 5.5 & $3.5-8.4$ & 23.8 & 1.2 & $0.3-3.6$ & NS \\
\hline Pericarditis & 16 & 4.2 & $2.5-6.8$ & 12.5 & 06 & $0.1-2.5$ & NS \\
\hline Total atrioventricular block & 12 & 3.1 & $1.7-5.8$ & 41.7 & 2.9 & $0.7-10.8$ & 0.08 \\
\hline Stroke & 6 & 1.6 & $0.9-3.5$ & 50 & 4 & $0.5-30.1$ & NS \\
\hline Interventricular septal rupture & 3 & 0.8 & $0.2-2.5$ & 66.7 & 7.9 & $0.4-467.3$ & NS \\
\hline Papillary muscle dysfunction/rupture & 3 & 0.8 & $0.2-2.5$ & 33.3 & 1.9 & $0.03-37.7$ & NS \\
\hline
\end{tabular}

nary embolism with no death was reported. The most frequent noncardiological complications were as follows: 22 cases of pneumonia (5.7\%) and 3 of digestive hemorrhage $(0.8 \%)$. Other secondary noncardiological diagnoses reported were as follows: chronic obstructive pulmonary disease (22 patients), gastritis (9), chronic renal failure (8), peripheral vascular disease (4), and peptic ulcer (3).

Of the 17 cases of ventricular fibrillation, 7 were of the primary type (1.8\%). Immediate lethality in primary ventricular fibrillation was observed in 3 of the 7 cases (42.9\%); in-hospital mortality was observed in 4 cases, because 1 patient, in whom the arrhythmia was reversed, had an anoxic cerebral lesion and died due to obstruction of the tracheal cannula. Primary ventricular fibrillation was associated with a chance of in-hospital death expressed as $\mathrm{OR}=5.4(95 \% \mathrm{CI}=0.9-37.2$; $\mathrm{P}=0.04$ ) as compared with the absence of complications. The
10 cases of secondary ventricular fibrillation in the sample had a $90 \%$ lethality with $\mathrm{OR}=84.2(95 \% \mathrm{CI}=10.8-3,701.6$; $\mathrm{P}<0.0001$ ) as compared with the lack of complications.

Electrocardiography was performed in 360 patients (93.8\%; 95\% CI=90.7-95.9). The electrocardiographic pattern of localization of acute myocardial infarction was as follows: anterior wall in 151 cases (39.3\%); inferior wall in $129(33.6 \%)$; acute myocardial infarction with no $\mathrm{Q}$ wave in 60 cases (15.6\%); and left bundle-branch block (LBBB) pattern in 12 cases (3.1\%). In 24 patients (6.3\%), electrocardiography was not performed (5 patients) or the result was not available in the medical records (19 patients); in the remaining 8 cases $(2.1 \%)$, electrocardiography was not performed, but acute myocardial infarction was ruled out. Lethality according to the electrocardiographic pattern was as follows: anterior $-18.5 \%$; inferior - $14.7 \%$; no Q wave - 
$11.7 \%$; and LBBB $-33.3 \%$. Lethality in the cases with no electrocardiogram or with an ignored result was particularly high $(75 \%)$ with $\mathrm{OR}=14.7(95 \% \mathrm{CI}=5.3-46.7 ; \mathrm{P}<0.0000001)$ as compared with the simple performance of electrocardiography, regardless of the resulting pattern. Right ventricular acute myocardial infarction was reported in 13 patients $(3.4 \%), 1$ of whom died (lethality $=7.7 \%$ ).

Measurement of cardiac enzymes was reported in 289 patients $(75.3 \%$; $95 \% \mathrm{CI}=70.6-79.4)$.

The use of chest radiography was reported in 190 patients $(49.5 \% ; 95 \% \mathrm{CI}=44.4-54.6)$, with a frequency similar to that of the echocardiography (175 patients; $45.6 \% ; 95 \%$ $\mathrm{CI}=40.5-50.7)$. Early exercise testing prior to hospital discharge was used in only 30 patients $(7.8 \%$; $95 \% \mathrm{CI}=5.4$ 11.1).

In the sample, 51 patients $(13.3 \% ; 95 \% \mathrm{CI}=10.1-17.2)$ underwent cardiac catheterization, 19 of whom $(37.5 \%)$ underwent the procedure out of the hospital of origin, but still during the hospitalization that generated AIH. The university-affiliated hospitals showed the highest use of catheterization (48.4\%). In-hospital lethality of the cases undergoing catheterization was $2 \%$. Generally, a significant variation in the use of diagnostic interventions was observed among the hospitals studied.

Table III shows the frequency of some therapeutic interventions in the sample; the percentage of information ignored was lower. The use of the intensive care unit or the coronary care unit (ICU/CCU) represents hospitalization during any period of the hospitalization studied. Coronary angioplasty and myocardial revascularization during hospitalization for acute myocardial infarction was infrequent; the 8 angioplasties performed included the only patient undergoing primary mechanical reperfusion in the sample, who died. In this table, the term ACE inhibitor refers to the group of drugs inhibiting the angiotensin-converting enzyme. Of the 75 patients undergoing pharmacological thrombolysis, 68 underwent the intervention at the same hospital that issued the $\mathrm{AIH}$, and 7 patients underwent the intervention at other places. A significant variation in regard to the use of therapeutic interventions was observed in the sample, except for acetylsalicylic acid and nitrates.
Table IV shows the results of the final logistic model of the study of risk variation in in-hospital death. Modeling controlled the variables expressing the severity of infarction (including Killip class on admission, age, sex, and electrocardiographic pattern of acute myocardial infarction), complications, comorbidities (including diabetes), admission to ICU/CCU, and use of interventions. The variables independently associated with an increased chance of death were as follows: increasing age group, increasing Killip class on admission, diabetes mellitus, recurring ischemia, ventricular tachycardia, ventricular fibrillation, and electrocardiography ignored or not performed. The use of acetylsalicylic acid, beta-blockers, and ACE inhibitors was associated with a lower chance of death. The option to maintain Killip II in the model, although with no statistical significance, was based on the biological plausibility of a higher risk of death as compared with that of the reference category Killip I, and also on the fact that its inclusion or exclusion did not change the estimates of the other parameters.

The variable electrocardiography ignored or not performed (comprising the cases in which the exam was not performed or no information existed about its results) was included as a possible indicator of problems with care or of the quality of information. Not performing electrocardiography when acute myocardial infarction was suspected should be considered an indicator of a deficient treatment system, although in some cases, its severity with rapid evolution to death may have been a factor of difficulty.

The concordance of the model shown was $90.1 \%$, and no random effect at the level of hospitals was detected. The tests for interaction between variables did not suggest its presence (the tests were systematically nonsignificant). The analysis of residues was performed and the withdrawal of extreme cases did not substantially modify the estimates, showing the stability of the model.

Generally, the profile of the results reported from the exploratory analysis to modeling was similar in the sample as a whole and in the subgroup of cases of confirmed/possible acute myocardial infarction, emphasizing that most cases met the criteria for confirmation of acute myocardial infarction, which neither interfered with modeling nor reached

\begin{tabular}{|c|c|c|c|c|c|c|c|}
\hline Intervention & f & $\%$ & IC $95 \%$ & Lethality (\%) & $\mathrm{OR}^{1}$ & $95 \% \mathrm{CI}$ & $\mathrm{p}$ \\
\hline Use of ICU or CCU & 312 & 81.3 & $76.9-85$ & 19.2 & 0.8 & $0.4-1.7$ & NS \\
\hline Coronary angioplasty & 8 & 2.1 & $0.97-4.2$ & 12.5 & 0.6 & $0.01-1.7$ & NS \\
\hline Myocardial revascularization & 4 & 1 & $0.3-2.8$ & 25 & 1.4 & $0.03-17.8$ & NS \\
\hline Acetylsalicylic acid & 332 & 86.5 & $82.5-89.6$ & 14.2 & 0.1 & $0.03-0.2$ & $<0.000001$ \\
\hline Oral or I.V. nitrate, or both & 315 & 82 & $77.7-85.7$ & 14.8 & 0.2 & $0.1-0.4$ & 0.000001 \\
\hline SC or I.V. heparin, or both & 312 & 81.3 & $76.9-85$ & 16.4 & 0.3 & $0.2-0.7$ & 0.0007 \\
\hline ACE inhibitor & 243 & 63.3 & $58.2-68.1$ & 14.8 & 0.5 & $0.3-0.8$ & 0.004 \\
\hline Beta-blocker & 188 & 49 & $43.9-54.1$ & 8 & 0.2 & $0.1-0.4$ & $<0.000001$ \\
\hline Calcium channel blocker & 117 & 30.5 & $26-35.4$ & 14.5 & 0.7 & $0.4-1.3$ & NS \\
\hline I.V. thrombolysis & 75 & 19.5 & $15.8-23.9$ & 13.3 & 0.6 & $0.3-1.3$ & NS \\
\hline Lidocaine & 35 & 9.1 & $6.5-12.6$ & 34.3 & 2.7 & $1.2-6$ & 0.009 \\
\hline
\end{tabular}




\begin{tabular}{|c|c|c|c|}
\hline \multicolumn{4}{|c|}{$\begin{array}{c}\text { Table IV - Final logistic model to study the risk of in-hospital death in } \\
\text { the sample of acuite myocardial infarction }\end{array}$} \\
\hline Variable & OR & $95 \% \mathrm{CI}$ & $\mathrm{p}$ \\
\hline \multicolumn{4}{|l|}{ Age group } \\
\hline 61 to 80 years & 2.5 & $1.2-5.3$ & 0.02 \\
\hline$>80$ years & 9.6 & $1.95-47.5$ & 0.005 \\
\hline \multicolumn{4}{|l|}{ Killip class on admission } \\
\hline Killip II & 1.9 & $0.5-7.2$ & NS \\
\hline Killip III & 6 & $1.4-25.9$ & 0.02 \\
\hline Killip IV & 26.5 & $2.9-242.1$ & 0.004 \\
\hline Diabetes & 2.4 & $1.1-5.1$ & 0.03 \\
\hline Not performed/ignored ECG & 11.8 & $3.5-39.9$ & 0.0001 \\
\hline Ventricular tachycardia & 8.5 & $2.5-29.6$ & 0.0007 \\
\hline Ventricular fibrillation & 34 & $7.9-146.9$ & 0.0001 \\
\hline Recurring ischemia & 2.7 & $1.2-6.2$ & 0.02 \\
\hline Use of acetylsalicylic acid & 0.3 & $0.1-0.8$ & 0.01 \\
\hline Use of beta-blocker & 0.3 & $0.1-0.7$ & 0.005 \\
\hline Use of ACE inhibitor & 0.4 & $0.2-0.95$ & 0.04 \\
\hline
\end{tabular}

statistical significance. The option to analyze the sample as a whole was chosen because it does not interfere with its representativity and provides more precise estimates.

\section{Discussion}

The great contribution of this study was the fact that it represents a random sample of all hospitalizations recorded in the SUS with the diagnosis of acute myocardial infarction, establishing a picture with the least possible bias about what occurred in the municipality of Rio de Janeiro in regard to acute myocardial infarction in the period studied.

In general, the $20.6 \%$ lethality found in the sample is very far from the reduced figures reached in randomized clinical trials ${ }^{15}$, or in selected centers ${ }^{7,13}$, or estimated based on a projection of efficacy of the technologies available for treating the cases ${ }^{27}$. However, other international studies of nonselected cases have reported high in-hospital lethality associated with acute myocardial infarction. In the USA, the second National Registry of Myocardial Infarction from 1994 to 1998 reported $19.7 \%$ of deaths when no cases were excluded ${ }^{27}$. European multicenter studies reported $18 \%$ to $21.7 \%$ of deaths in the $1990 \mathrm{~s}^{10-12}$.

Of the national studies of nonselected cases, 2 using AIH stand out with 17.1\% lethality in the state of São Paulo in $1997^{18}$ and $18.4 \%$ in the state of Rio de Janeiro in $1995^{22}$. A recent study reported a 30 -day mortality of $22 \%$ in a university-affiliated hospital in the city of Botucatu, in the state of São Paulo ${ }^{28}$. On the other hand, Passos et al ${ }^{13}$ reported a 12.9\% lethality in the city of Salvador from 1993 to 1994. Those authors, however, selected the participating hospitals according to criteria quality of information and treatment.

The structure of sex and age group of the sample was similar to that reported in the literature for national studies ${ }^{13,22,27}$ and did not vary in the sample. The median delta time observed was similar to that of another Brazilian study ${ }^{27}$.
The prevalence of arterial hypertension was similar to that of another North American study ${ }^{28}$ and lower than that reported by Passos et al $(67 \%)^{13}$ and by Zornoffet al $(63 \%)^{28}$. The prevalences of diabetes and dyslipidemia were similar to those in other studies ${ }^{13,28,29}$. The percentage of ignored risk factors was high and, most of the time, represented the lack of information in medical records.

The severity of our cases of acute myocardial infarction was detailed in another publication ${ }^{24}$ and does not seem higher than that reported by other groups. The percentage of Killip class I on admission observed was much greater than the 56\% reported in the English Nottingham Heart Attack Register ${ }^{12}$, and much closer to the $77.8 \%$ of the study by Passos et al ${ }^{13}$. This study from the Brazilian state of Bahia reported a $6.3 \%$ lethality in the cases presenting in Killip class I on admission, which is approximately half of that observed in the present sample (tab. I).

The $1.8 \%$ incidence of primary ventricular fibrillation was lower than the $4.7 \%$ reported in the Worcester Heart Attack multicenter study, which found an associated inhospital lethality of $44 \%{ }^{30}$.

Variability in the use of catheterization depended on the availability of a hemodynamic laboratory at the hospital of AIH. However, some hospitals with no hemodynamics had patient management protocols that allowed the performance of the examination at another hospital, still during hospitalization. International studies have reported varied frequencies of use of cardiac catheterization during hospitalization in acute myocardial infarction, usually greater than the mean of $13.3 \%$ observed in our sample (tab. III). European studies report a use of cardiac catheterization ranging from $32 \%$ to $53 \%{ }^{11,16}$. A variation in use among the North American entities participating in the GUSTO Study was reported ranging from 52 to $81 \%{ }^{15}$.

Although the use of acetylsalicylic acid has been widespread $(86.5 \%)$ in this study, it was lower than that expected, because of its almost universal indication in acute myocardial infarction, simple administration, low cost, and confirmed efficacy ${ }^{3,31}$. Another publication referring to this sample ${ }^{17}$ reported that only $72.3 \%$ of the patients treated with acetylsalicylic acid received the treatment from the first day of hospitalization; in addition, that study reported a loss of opportunity to perform thrombolysis in $32 \%$ of the cases with an explicit indication for treatment. This fact has also been reported in other countries: the National Registry of Myocardial Infarction- 2 showed that $24 \%$ of the patients with a clear indication for thrombolysis received no therapy ${ }^{32}$. The general frequency of use of pharmacological thrombolysis in that registry was $35 \%$, and, in a Norwegian study, it was $32 \%{ }^{10}$.

Two national studies reported $36.8 \%$ and $39 \%$ of thrombolysis, respectively ${ }^{13,28}$. Another study estimated that the percentage of indication of thrombolysis in acute myocardial infarction in Brazil was approximately $40 \%$ of the cases ${ }^{27}$. A recent national study reported $41 \%$ of use of pharmacological thrombolysis and $15 \%$ of primary angioplasty in acute myocardial infarction; and yet, in-hospital 
mortality was high: among the patients undergoing primary angioplasty it was $18.5 \%{ }^{33}$. The CENIC Registry of the Brazilian Society of Hemodynamics and Interventional Cardiology ${ }^{34}$ reported an in-hospital mortality of $5.9 \%$ in its cases of primary angioplasty.

In the literature, the use of beta-blockers has ranged from $35 \%$ to $78 \%$, and, frequently, no route of administration has been reported ${ }^{7,8,11-15,28}$. In our sample, the administration of beta-blockers has been almost restricted to the oral route ${ }^{17}$.

The use of ACE inhibitors was high (63.3\% of the cases), similar to that of a North American registry of cases of acute myocardial infarction $(59.3 \%)^{8}$, greater than the $43 \%$ reported in Switzerland ${ }^{15}$ and the $41 \%$ reported in another Brazilian study ${ }^{28}$.

In general, the use of calcium channel blockers was high, despite the lack of scientific evidence of its efficacy in the acute phase of acute myocardial infarction, except for specific cases.

The great variability in the use of technologies with well-established scientific-based indications and efficacy has been the object of analysis in other countries ${ }^{5,7,8}$. Apparently, one of the major explanations for this variability does not lie in the variability of indication of the interventions, but in different levels of adherence to protocols based on scientific evidence of efficacy, or even on its knowledge.

Regarding multivariate modeling, the independent associations found among the more advanced age group, diabetes, and increasing Killip class on admission are in accordance with those found in the literature ${ }^{3,4}$.

Despite the possible limitations regarding the diagnosis of ventricular tachycardia, it remained associated with a high chance of in-hospital death on multivariate analysis. Both the effects of primary and secondary ventricular fibrillation were analyzed; both persisted associated with a greater chance of death, but the reduced number of cases led to less accurate estimates. The recurring ischemia variable was not statistically significant on bivariate analysis (tab. IV), but was included in the modeling because of the biological plausibility of the association with a higher risk of death ${ }^{4}$, which was shown in the logistic model.

The interventions associated with a smaller chance of death were the use of acetylsalicylic acid, beta-blockers, and ACE inhibitors. The use of thrombolysis was not statistically significant, which may be related to the size of the sample. The possible presence of a doubtful indication of an intervention (which may appear when analyzing the effect of the interventions out of the controlled clinical assays) was controlled with the inclusion in the model of variables related to the severity of the case and the indication of interventions.

In our study, the possibility of the existence of an internal correlation at the level of the hospitals was investigated with hierarchic modeling, which detected no significant random effect. This may be related to the size of the sample, both from the point of view of the number of observations of the upper level (the hospitals) and the number of observations of the first level (the case), because the calculus of the sample was based on the proportion of deaths in the municipality as a whole. Anyway, this fact confirms the choice of the logistic model.

In conclusion, despite the high overall lethality, the profile of severity, major risk factors, and the frequency of the complications studied were similar or more favorable than those found in other studies. Diabetes, advanced age group, Killip class, recurring ischemia, ventricular tachycardia, and ventricular fibrillation were associated independently with an increased chance of in-hospital death. The use of acetylsalicylic acid, beta-blockers, and ACE inhibitors was associated with a smaller chance of in-hospital death. The underutilization of effective interventions suggests the possibility of better outcomes in the hospital treatment of acute myocardial infarction in the municipality studied.

\section{References}

1. Ministério da Saúde. Sistema de Informações sobre Mortalidade - SIM/ DATASUS. http://www.datasus.gov.br

2. Lolio CA, Lotufo PA, Lira AC, Zanetta DMT, Massad E. Tendência da mortalidade por doença isquêmica do coração nas capitais de regiões metropolitanas do Brasil, 1979-89. Arq Bras Cardiol 1995; 64: 213-16.

3. ACC/AHA (American College of Cardiology/American Heart Association Task Force Report). 1999 Update: Guidelines for the Management of Patients With Acute Myocardial Infarction. Guideline. J Am Coll Cardiol 1999; 34 890-911.

4. Alexander RW, Pratt CM, Roberts R. Diagnosis and management of patients with acute myocardial infarction. In: Alexander RW, Schlant RC, Fuster V. Hurst's the Heart: Arteries and Veins. 9a ed. New York: McGraw-Hill; 1998; $1345-433$.

5. Consenso Brasileiro sobre Trombólise. Diretrizes da Sociedade Brasileira de Cardiologia sobre cuidados ao paciente infartado. Arq Bras Cardiol 1994; 63 (supl.II): 1-8.

6. Becker RC, Burns M, Gore JM, Lambrew C, French W, Rogers WJ. Early and predischarge aspirin administration among patients with acute myocardial infarction: current clinical practice and trends in the United States. J Thromb Thrombolysis 2000; 9: 207-15.

7. Scott IA, Eyeson-Annan ML, Huxley SL, West MJ. Optimising care of acute myocardial infarction: results of a regional quality improvement project. J Qual Clin Pract 2000; 20: 12-19.

8. O'Connor GT, Quinton HB, Traven ND, et al. Geographic variation in the treatment of acute myocardial infarction: the Cooperative Cardiovascular Project. JAMA 1999; 281: 627-33.

9. Venturini F, Romero M, Tognoni G. Patterns of practice for acute myocardial infarction in a population from ten countries. Eur J Clinical Pharmacol 1999; 54: 877-86.

10. Reikvam A, Aursnes I. Hospital mortality from acute myocardial infarction has been modestly reduced after introduction of thrombolytics and aspirin: results from a new analytical approach. European Secondary Prevention Study Group. J Clin Epidemiol 1999; 52: 609-13.

11. Mahon NG, O'Rorke C, Codd MB, McCann HA, McGarry K, Sugrue DD. Hospital mortality of acute myocardial infarction in the thrombolytic era. Heart 1999; 81: 478-82.

12. Brown N, Young T, Gray D, Skene AM, Hampton JR. Inpatient deaths from acute myocardial infarction, 1982-92: analysis of data in the Nottingham Heart Attack Register. Br Med J 1997; 315: 159-64.

13. Passos LCS, Lopes AA, Souza LAM, et al. Preditores da mortalidade hospitalar na era trombolítica para o infarto agudo do miocárdio em Salvador(BA). Arq Bras Cardiol 1997; 68: 249-55. 
14. McGovern PG, Pankow JS, Shahar E, et al. Recent trends in acute coronary heart disease. Mortality, morbidity, medical care and risk factors. N Engl J Med 1996; 334: 884-90.

15. Pilote L, Califf RM, Sapp S, et al. Regional variation across the United States in the management of acute myocardial infarction. NEngl J Med 1995; 333:565-72.

16. Bourquin MG, Wietlisbach C, Rickenbach M, Perret F, Paccaud F. Time trends in the treatment of acute myocadial infarction in Switzerland from 1986 to 1993: do they reflect the advances in scientific evidence from clinical trials? J Clin Epidemiol 1998; 51: 723-32

17. Escosteguy CC, Portela, MC, Vasconcellos MTL. Pharmacological management of acute myocardial infarction in the municipal district of Rio de Janeiro. Rev Paul Med 2001; 119: 193-9.

18. Marcopito LF, GoldfederAJ, Schenkman S. Infarto agudo do miocárdio no estado de São Paulo. Mortes ocorridas em hospitais, de 1979 a 1996, e letalidade hospitalar no SIH/SUS, de 1984 a 1998. Arq Bras Cardiol 2000; 74: 39-42.

19. Every NR, Frederick PD, Robinson M, Sugarman J, Bowlby L, Barron HV. A comparison of the National Registry of Myocardial Infarction 2 with the cooperative cardiovascular project. J Am Coll Cardiol 1999, 33: 1886-94.

20. Vaccarino V, Parsons L, Every NR, Barron HV, Krumholz HM. Sex-based differences in early mortality after myocardial infarction. National Registry of Myocardial Infarction 2 Participants. N Engl J Med 1999; 341: 217-25.

21. Goldberg RJ, Yarzebski J, Lessard D, Gore JM. A two-decades (1975 to 1995) long experience in the incidence, in-hospital and long-term case-fatality rates of acute myocardial infarction: a community-wide perspective. J Am Coll Cardiol 1999; 33: 1533-39.

22. Escosteguy CC, Medronho RA, Portela MP. Avaliação da letalidade hospitalar do infarto agudo do miocárdio no estado do Rio de Janeiro através do uso do Sistema de Informações Hospitalares/SUS. Cad Saúde Colet 1999; 7: 39-59.

23. Cochran WG. Sampling Techniques. 3a ed. New York: John Wiley \& Sons; 1977.

24. Escosteguy CC. Avaliação da qualidade da assistência hospitalar ao infarto agudo do miocárdio no município do Rio de Janeiro. Tese de Doutorado. Rio de Janeiro: Escola Nacional de Saúde Pública/FIOCRUZ; 2000.
25. WHO MONICA (Multinational Monitoring of Trends and Determinants in Cardiovascular Disease) Project. Myocardial Infarction and Coronary Death in the World Health Organization MONICA Project. Registration Procedures, Event Rates, and Case-Fatality Rates in 38 Populations from 21 Countries in Four Continents. Circulation 1994; 90: 583-612.

26. Killip T \& Kimball JT. Treatment of myocardial infarction in a coronary care unit: a two experience with 250 patients. Am J Cardiol 1967; 20: 457-64.

27. Krauss Silva L, Escosteguy CC, Machado CV. Metodologia para a estimativa de padrões de qualidade: o caso do infarto agudo do miocárdio. Cad Saúde Pública 1996; 125 (supl.II): 71-83.

28. Zornoff LAM, Paiva SAR, Assalin VM et al. Perfil clínico, preditores de mortalidade e tratamento de pacientes após infarto agudo do miocárdio, em hospital terciário universitário. Arq Bras Cardiol 2002; 78: 396-400.

29. Guadagnoli E, Hauptman PJ, Ayanian JZ, et al. Variation in the use of cardiac procedures after acute myocardial infarction. N Eng J Med, 1995; 333: 573-8.

30. Thompson CA, Yarzebski J, Goldberg RJ, et al. Changes over time in the incidence and case-fatality rates of primary ventricular fibrillation complicating acute myocardial infarction: perspectives from the Worcester Heart Attack Study. Am Heart J 2000; 139: 1014-21.

31. ISIS-2 Collaborative Group. Randomised trial of intravenous streptokinase, oral aspirin, both or neither among 17187 cases of suspected acute myocardial infarction. Lancet 1988; i: 349-60.

32. Barron HV, Rundle A, Gurwitz J, Tiefenbrunn A. Reperfusion therapy for acute myocardial infarction: observations from the National Registry of Myocardial Infarction 2. Cardiol Rev 1999; 7: 156-60.

33. Leite RS, Krepsky AM, Gottschall CAM. Efetividade da angioplastia primária no tratamento do infarto agudo do miocárdio. Análise hospitalar e tardia de 135 casos consecutivos. Arq Bras Cardiol 2001; 3: 205-12.

34. Mattos LA, Sousa AGMR, Neto CC, et al. Revascularização coronária percutânea no infarto agudo do miocárdio sem o uso prévio de agentes trombolíticos: análise dos resultados hospitalares no registro CENIC/SBHCI. Rev Bras Cardiol Invas 1999; 7:7-12 